\title{
PENGARUH BRAND IMAGE, CONSUMER SATISFACTION, ELECTRONIC WORD OF MOUTH TERHADAP NIAT MENGGUNAKAN KEMBALI
}

\author{
Ni Putu Siska Yundari ${ }^{1}$ \\ I Made Wardana ${ }^{2}$
}
1,2 Fakultas Ekonomi dan Bisnis Universitas Udayana (Unud), Bali, Indonesia e-mail: putusiskayundari@gmail.com

\begin{abstract}
ABSTRAK
Sasaran dari penelitian ini ialah bertujuan guna untuk memberikan penjelasan mengenai pengaruh brand image terhadap niat menggunakan kembali, consumer satisfaction terhadap niat menggunakan kembali, electronic word of mouth terhadap niat menggunakan kembali. Wilayah Kota Denpasar dipilih sebagai lokasi penelitian dengan menyebarkan kuesioner kepada sampel penelitian sebanyak 104 responden yang dipilih purposive sampling. Adapun indikator dalam penelitian ini sebanyak 13, yang dianalisis menggunakan alanisis regresi linear berganda dengan hasil penelitian yang memperlihatkan jika brand image, consumer satisfaction, dan electronic word of mouth mampu berpengaruh positif dan signifikan secara simultan serta parsial terhadap niat menggunakan kembali jasa Go-Food di Kota Denpasar. Penelitian ini memberi implikasi teoritis mengenai bagaimana pentingnya brand image, consumer satisfaction, dan electronic word of mouth dalam mempengaruhi niat menggunakan kembali pada jasa Go-Food di Kota Denpasar dan implikasi praktis dari penelitian ini mampu menyampaikan informasi kepada konsumen yang digunakan sebagai dasar pertimbangan didalam mengambil keputusan untuk menggunakan kembali jasa Go-Food di Kota Denpasar.

Kata kunci : brand image, consumer satisfaction, electronic word of mouth, niat menggunakan kembali
\end{abstract}

\begin{abstract}
The purpose of this study is to provide an explanation of the effect of brand image on reuse intention, consumer satisfaction on reuse intention, electronic word of mouth on reuse intention. This research was counducted in Denpasar City by distributing questionnaires to a sample of 104 respondents who were selected by purposive sampling. The indicators in this study were 13, which were analyzed using multiple linear regression analysis with the results of research that showed that brand image, consumer satisfaction, electronic word of mouth were able to have positive and significant effect simultaneously and partially on the reuse intention Go-Food in Denpasar City. The study provides theoretical implications on how the importance of brand image, consumer satisfaction, electronic word of mouth in influencing the intention to reuse Go-Food services in Denpasar City and the partical implications of this research are able to provide information to consumers that are used as consideration in making decisions to reuse Go-Food services in Denpasar City.

Key Word : brand image, consumer satisfaction, electronic word of moth, reuse intention
\end{abstract}




\section{PENDAHULUAN}

Bertambahnya kebutuhan primer maupun sekunder dalam kehidupan masyarakat semakin memacu akal manusia utuk menciptakan inovasi-inovasi baru pada saat ini. Inovasi merupakan sebuah gagasan atau ide-ide yang belum pernah ada atau dicetuskan sebelumnya. Berbagai inovasi di era globalisasi ini diciptakan guna untuk memenuhi kebutuhan masyarakat dan melakukan perubahan secara terus menerus, salah satunya adalah perubahan dalam bidang teknologi. Salah satu perubahan teknologi yang memberikan hasil dan sangat berpengaruh dalam kelancaran aktivitas masyarakat pada saat ini adalah teknologi transportasi. Seiring dengan berjalannya kemajuan teknologi transportasi, terciptanya kemudahan dalam aktivitasnya, menjadi semakin praktis dan lebih modern merupakan salah satu perubahan dari masyarakat Indonesia (Parastanti dkk.,2014). Banyak masyarakat Indonesia yang memiliki kesibukan dan waktu yang relative sedikit dalam meluangkan waktunya untuk melakukan kegiatan yang dianggap kurang praktis, sehingga muncul sebuah gagasan ide bisnis dalam bidang transportasi yaitu ojek online.

Ojek online merupakan sarana transportasi umum yang menggunakan layanan aplikasi dan internet untuk memesannya, dengan adanya kemajuan teknologi pada saat ini kita bisa mendapatkan ojek melalui smartphone yang kita miliki. Para pengusaha ojek online selalu berusaha untuk berinovasi dan mengintip apa yang menjadi kebutuhan masyarakat, dengan harapan agar masyarakat selalu merasa membutuhkan pelayanan jasa tersebut dan berdampak terhadap jangka panjang yang membuat konsumen tetap memiliki minat untuk 
menggunakan kembali terhadap jasa yang telah ditawakan sebelumnya. Niat menggunakan kembali merupakan suatu perilaku yang dilakukan oleh konsumen, setelah sebelumnya konsumen pernah melakukan pembelian atas produk atau jasa yang telah ditawarkan.

Niat menggunakan kembali dapat memberikan dampak positif terhadap perusahaan karena perusahaan memiliki nilai lebih dimata konsumen sehingga konsumen ingin melakukan pembelian kembali pada perusahaan tersebut. Menurut Srivastava dan Sharma (2013) niat menggunakan kembali diartikan dengan keputusan seseorang untuk menggunakan pelayanan jasa kembali dan keputusan untuk terlibat didalam aktivitas masa depan dengan penyedia layanan, serta bentuk kegiatan apa yang dapat dilakukan. Jika terdapat niat konsumen untuk menggunakan kembali suatu produk atau pelayanan jasa, hal tersebut menandakan bahwa perusahaan memiliki brand yang bagus dibenak konsumen sehingga hal tersebut harus diperhatikan karena brand dari perusahaan akan menunjukkan image, nama dan kualitias dari perusahaan itu sendiri.

Menurut Shahrinaz et al. (2016) brand image didefinisikan sebagai informasi yang terkait dengan merek dalam memori customer atau dengan kata lain asosiasi dan kepercayaan yang konsumen miliki terhadap merek tertentu, sedangkan menurut Eriza (2017) brand image didefinisikan sebagai keseluruhan peristiwa yang berkaitan dengan merek, berada dalam ingatan konsumen serta dapat mempersentasikan keseluruhan pemahaman konsumen kepada merek yang tercipta karena informasi serta pengalaman konsumen. Penelitian terdahulu dilakukan oleh Ayutthaya (2013) membuktikan jika brand image mempunyai 
pengaruh positif serta signifikan terhadap niat menggunakan kembali (repurchase intention), akan tetapi berbanding terbalik atas penelitian yang ditemukan oleh Vigripat dan Chan (2007) yang membuktikan jika brand image tidak memiliki pengaruh signifikan terhadap niat menggunakan kembali. Pernyataan tersebut dapat diasumsikan bahwa brand image yang baik belum tentu dapat mempengaruhi niat konsumen untuk menggunakan kembali suatu produk ataupun jasa yang sudah mereka gunakan sebelumnya.

Consumer satisfaction atau yang lebih dikenal dengan kepuasan konsumen merupakan sesuatu yang didapatkan lebih oleh konsumen dari produk atau pelayanan yang diberikan oleh perusahaan. Jika kualitas pelayanan bagus dan sesuai dengan ekspetasi konsumen maka konsumen akan merasakan puas, sebaliknya jika kualitas produk atau pelayanan yang diberikan tidak seperti dengan apa yang menjadi keinginan konsumen, maka konsumen akan merasakan kekecewaan. Penelitian terdahulu yang telah dilakukan oleh Huang et al. (2014) membuktikan jika consumer satisfaction mampu berpengaruh signifikan terhadap niat menggunakan kembali (repurchase intention), akan tetapi berbanding terbalik dengan hasil penelitian yang telah dilakukan oleh Prastiwi (2016) penelitian tersebut menyatakan jika consumer satisfaction tidak memiliki pengaruh yang signifikan terhadap niat mengguakan kembali. Hal tersebut diasumsikan apabila konsumen yang merasa puas belum pasti mereka akan menggunakan kembali produk atau layanan jasa yang telah mereka gunakan sebelumnya.

Tidak sedikit masyarakat yang memberikan komentar-komentar positif mengenai keberadaan ojek online, karena dengan adanya ojek online masyarakat 
merasa lebih dimudahkan. e-WOM merupakan keseluruhan komunikasi infornal yang diperuntukan kepada konsumen yang berkaitan dengan pemakaian atau karakteristik barang serta jasa tertentu atau penjualan mereka melewati teknologi berbasis internet Sotiriadis dan Van Zyl (2013). Komunikasi e-WOM menggunakan media electronic mengakibatkan konsumen memperoleh informasi mengenai jasa maupun produk dari orang yang dikenalnya, selain itu konsumen juga dapat memperoleh informasi melalui masyarakat lain yang area geografisnya berlainan, yang mempunyai pengalaman tentang jasa ataupun produk yang sama Eriza (2017). Penelitian yang dikemukakan oleh Liang et al. (2017) membuktikan apabila $e-W O M$ mempunyai pengaruh yang signifikan terhadap niat menggunakan kembali.

Dewasa ini, salah satu bisnis ojek online yang sedang marak di Negara Indonesia adalah PT. Aplikasi Karya Anak Bangsa atau oleh masyarakat lebih dikenal dengan memakai sebutan Go-Jek, Go-Jek adalah pelayanan jasa transportasi online yang pertama kali ada di Indonesia. System manajemen operasinal dari Go-Jek bersama-sama menyatukan teknologi moderen startup, keseluruhan driver Go-Jek wajib mengantongi handphone dengan aplikasi serta GPS yang selalu aktif. Ketika konsumen order jasa melewati aplikasi Go-Jek panggilan tersebut akan menggetarkan handphone driver yang terhubung hingga pesanan tersebut dipenuhi. Awal berdirinya Go-Jek berada di Jakarta, kemudian seiring berjalannya waktu meluas ke berbagai daerah lainnya seperti Yogyakarta, Surabaya, Solo, Semarang, Padang, Manado, Bandar Lampung, Balikpapan, Makassar, Medan, Palembang, Pekan Baru dan Bali. 
PT. Aplikasi Karya Anak Bangsa pada tahun 2016 dan 2017 berhasil mendapatkan penghargaan Top Brand Award dalam kategori transportasi online, Top Brand Award yaitu merek-merek terbaik pilihan konsumen yang nantinya akan diberikan suatu penghargaan, Top Brand Award tersebut didasarkan atas hasil survei dari Frontier Consulting Group.

Tabel 1.

Top Brand Index Kategori Transportasi Online Tahun 2016 dan 2017

\begin{tabular}{lcclcc}
\hline & $\mathbf{2 0 1 6}$ & & \multicolumn{3}{c}{$\mathbf{2 0 1 7}$} \\
\hline Merek & TBI (\%) & TOP & Merek & TBI (\%) & TOP \\
\hline Go-Jek & 80.8 & TOP & Go-Jek & 59.2 & TOP \\
Grab & 14.7 & TOP & Grab & 28.2 & TOP \\
Uber & 1.7 & & Uber & 8.0 & \\
Blu-Jek & 1.7 & & Blu-Jek & 0.3 & \\
\hline Sumber: & & & &
\end{tabular}

Sumber: Top Brand Index 2016 dan 2017

Berdasarkan hasil survei yang dipublikasikan oleh Top Brand dalam kategori transportasi online dapat dibuktikan bahwa Go-Jek selalu menjadi pilihan dari konsumen Indonesia selama dua dekade terakhir. Akan tetapi bila diperhatikan TBI dari Go-Jek setiap tahun mengalami penurunan hal tersebut mengindikasikan bahwa kepuasan konsumen terhadap Go-Jek mulai berkurang, brand image dari PT Aplikasi Karya Anak Bangsa semakin meredup yang mengakibatkan sedikit tidaknya terjadi penurunan terhadap niat untuk menggunakan kembali jasa dari PT. Aplikasi Karya Anak Bangsa.

Setelah berhasil memperkenalkan bisnis ojek onlinenya kepada masyarakat Indonesia, CEO PT. Aplikasi Karya Anak Bangsa mulai melebarkan sayap bisnisnya menyasar bidang lain, adapun bisnis barunya saat ini yang marak diperbincangkan adalah Go-Food. Go-Food merupakan bagian dari fitur Go-Jek yang diliris pada bulan Maret 2015, Go-Food sendiri merupakan suatu pelayanan jasa yang menawarkan antar dan pesan makanan. Dikutip dari laman 
(https://www.go-food.co.id/) Go-Food melakukan kerja sama dengan 37.000 rumah makan yang berada di seluruh Indonesia. Sebagian besar konsumen Indonesia merasa terbantu dengan adanya Go-Food karena konsumen tidak perlu lagi pergi jauh-jauh, mengantrai kerumah makan, dan menghabiskan banyak waktu, akan tetapi dikutip dari laman (http://keluhan-gojek.ojekgratis.com/) selain merasa terbantu disisi lain terdapat beberapa customer yang merasa kecewa dengan pelayanan yang telah diberikan, dengan adanya hal mengakibatkan munculnya berbagai e-WOM yang beredar di sosial media dan bisa saja hal tersebut dapat mempengaruhi kepuasan konsumen serta niat untuk menggunakan kembali jasa dari Go-Food yang sebenarnya memiliki banyak fitur pelayanan yang mempermudah kehidupan masyarakat.

Pra survei dilakukan untuk mengetahui seberapa besar minat konsumen dalam menggunakan kembali jasa Go-Food, adapun kriteria respondennya merupakan konsumen yang sudah pernah menggunakan jasa Go-Food sebelumnya. Wilayah Kota Denpasar merupakan wilayah yang dipilih sebagai lokasi untuk dilakukannya pra survei, Kota Denpasar yang dipilih karena Kota Denpasar memiliki tingkat kepadatan penduduk tertinggi di Pulau Bali yaitu sekitar 788.589 jiwa (bali.bps.go.id, 2018). Adapun pra survei yang telah kami lakukan 24 dari 30 responden menyatakan berniat untuk menggunakan kembali jasa Go-Food dan 6 responden lainnya menyatakan tidak akan menggunakan kembali jasa Go-Food di Kota Denpasar. Hal tersebut dinyatakan bahwa lebih banyak konsumen yang berniat untuk menggunakan kembali jasa Go-Food di Kota Denpasar, dengan tumbuhnya niat konsumen untuk menggunakan kembali 
jasa Go-Food di Kota Denpasar menjadi suatu hal atau fenomena yang menarik untuk diteliti lebih lanjut. Fenomena brand image, consumer satisfaction, dan electronic word of mouth dalam mempengaruhi tumbuhnya niat menggunakan kembali terhadap jasa Go-Food diasumsikan memiliki peran atau pengaruh yang signifikan. Untuk meyakinkan dan membuktikan hal tersebut maka dibutuhkan penelitian lebih lanjut dengan menggunakan variabel brand image, consumer satisfaction, electronic word of mouth serta niat menggunakan kembali terhadap jasa Go-Food di Kota Denpasar.

Penelitian ini terdapat rumusan masalah yaitu 1) bagaimana pengaruh brand image terhadap niat mengunakan kembali jasa Go-Food di Kota Denpsar; 2) bagaimanapengaruh consumer satisfaction terhadap niat menggunakan kembali jasa Go-Food di Kota Denpasar; 3) bagaimana pengaruh electronic word of mouth terhadap niat mengunakan kembali jasa Go-Food di Kota Denpasar. Penelitian ini bertujuan ialah untuk menjawab rumusan yang diajukan dalam penelitian ini. Manfaat penelitian secara teoritis yaitu dapat menjadi refrensi bagi penelitipeneliti selanjutnya dalam bidang yang terkait, sedangkan manfaat secara praktisnya dapat menjadi informasi sebagai bahan pertimbangan dalam pengambila keputusan bagi perusahaan PT. Aplikasi Karya Anak Bangsa.

Band image dikatakan sebagai persepsi seorang konsumen serta perferensi kepada merek yang terrefleksikan oleh berbagai macam persepsi merek yang berada dalam ingatan konsumennya Fauziah (2017). Brand image memiliki makna jika pertumbuhan didalam pasar akan mengajak konsumennya untuk lebih memikirkan brand image dibandingkan mencermati karakteristik produk yang 
ditawarkan, hal tersebut memperlihatkan jika terjadi kecendrungan konsumen akan memilah suatu produk yang diraih melewati berbagai sumber atau produk yang telah mereka kenal baik melalui pengalaman menggunakan produk Raharjo dan Amboningtyas (2017). Brand image merupakan sebuah mahkota dari setiap perusahaan, brand image dapat dibentuk melalui kepuasan yang dirasakan oleh para konsumennya, jika konsumen merasakan kepuasan mereka akan merekomendasikan jasa atau produk yang telah mereka gunakan sebelumnya, sehingga tidak menutup kemungkinan apabila mereka akan membawa calon konsumen baru dalam jumlah yang lebih banyak.

Consumer satisfaction didefinisikan sebagai overall consumer satisfaction yaitu mengenai komentar secara menyeluruh tentang seberapa puas serta tidak puas kepada total atribut produk maupun jasa (Rozak et al., 2012). Menurut pendapat Sembiring \& Kusumawati (2014) dengan mempertahankan pelanggan juga berarti mengharapkan pelanggan untuk melakukan pembelian kembali atas produk, baik barang maupun jasa pada saat kebutuhan yang muncul sewaktuwaktu. Jika pelayanan yang diberikan oleh perusahaan semakin baik maka konsumen juga akan merasakan kepuasan, berbeda dengan perusahaan yang telah memberikan pelayanan yang kurang memuaskan maka kepuasan konsumen juga akan semakin menurun.

Konsumen yang bersikap kritis sebelum melakukan pembelian akan membuat konsumen menggali lebih dalam informasi mengenai suatu produk yang dituju. e-WOM dapat dikerjakan dengan memberikan suatu review produk, memberikan rekomendasi kepada konsumen lainnya atau sharing pengalaman 
(Umamy dkk., 2016). Electronic word of mouth belum tentu berisi informasi yang akurat karena berasal dari sumber yang cendrung tidak dikenal (seperti sesama pengguna sosial media tertentu) namun $e-W O M$ memiliki kelebihan yaitu dapat disimpan sebagai arsip jika sewaktu-waktu dibutuhkan dan penyebarannya sangat cepat bahkan dapat meluas secara global (Humaira dan Wibowo, 2016).

Niat membeli kembali pada penelitian ini merupakan konteks dari niat membeli kembali (repurchase intention), Mowen dan Minor (2010) menyatakan bahwa definisi niat sebagai semua tindakan konsumen untuk memperoleh dan menggunakan barang atau jasa. Pada dasarnya niat menggunakan kembali merupakan sikap pelanggan yang merespon positif mengenai kualitas dari pelayanan suatu perusahaan serta memiliki minat untuk berkunjung kembali atau menggunakan kembali produk dari perusahaan yang sama (Putra dkk., 2014). Munculnya niat untuk menggunakan kembali terhadap suatu produk atau jasa diharapkan dapat membawa dampak yang positif terhadap keberhasilan produk dalam suatu perusahaan. Merek yang sudah melekat dihati konsumen dan membuat konsumennya puas terhadap produk tersebut maka akan mengakibatkan konsumen melanjutkan pembelian atau melakukan pembelian ulang (Nurhayati dan Murti 2012)

Berdasarkan penelusuran pada kajian pustaka dari beberapa para ahli dan hasil-hasil penelitian sebelumnya atau terdahulu, maka dapat disusun suatu kerangka konseptual sebagai dasar penentu dari hipotesis. Berikut merupakan gambaran kerangka konseptual pada penlitian ini: 


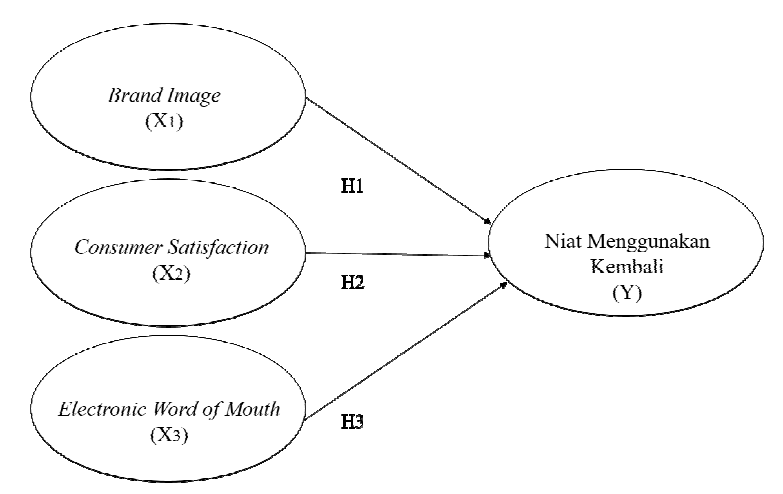

Gambar 1. Kerangka Konseptual Penelitian

Sumber: dikembangkan dari penelitian sebelumnya, 2018

Menurut penelitian yang dilakukan oleh Sari dan Santika (2013) menyatakan apabila perilaku konsumen yang semakin tertarik untuk menggunakan suatu produk, maka akan semakin baik pula brand image yang menempel pada produk tersebut. Penelitian yang dilakukan oleh Ayutthaya (2013), Aryadhe dan Rastini (2016), Soleha dkk. (2017) dan Apriyani (2013) yang menyatakan jika brand image mempunyai pengaruh yang signifikan terhadap pembentukan niat menggunakan kembali. Hasil empiris pada penelitian terdahulu, maka hipotesis yang dapat diadopsi dalam penelitian ini sebagai berikut:

$\mathrm{H}_{1}$ : Brand image berpengaruh positif dan signifikan terhadap niat menggunakan kembali

Penelitian terdahulu yang diteliti Kim dan Lough (2007) menyatakan bahwa consumer satisfaction berpengaruh positif terhadap niat menggunakan kembali, penelitian selanjutnya yang dikemukakan oleh Fang (2011) yang menjelaskan bahwa kepuasan konsumen paling dominan mempengaruhi niat menggunakan kembali. Sejalan dengan penelitian lainnya, untuk penelitian yang diteliti oleh Huang et al. (2014) dan Kusuma dan Suryani (2017) mengatakan jika consumer satisfaction atau yang lebih dikenal dengan kepuasan konsumen memiliki 
pengaruh signifikan terhadap niat menggunakan kembali. Berdasarkan hasil empiris pada penelitian terdahulu, maka dalam penelitian ini hipotesis yang dapat diajukan adalah:

$\mathrm{H}_{2}$ : Consumer satisfaction berpengaruh positif dan signifikan terhadap niat menggunakan kembali

Penelitian terdahulu telah diteliti oleh Liang et al. (2017) jika variabel eWOM berpengaruh signifikan terhadap niat menggunakan kembali, dan penelitian selanjutnya yang diteliti oleh Matute (2016) yang menyatakan e-WOM berpengaruh signifikan terhadap niat menggunakan kembali, dan hal yang serupa juga ditemukan dalam penelitian Arumsari and Ariyanti (2017) serta Torlak et al. (2014) penelitian tersebut menyatakan bahwa $e-W O M$ berpengaruh signifikan terhadap niat menggunakan kembali. Hasil empiris pada penelitian terdahulu, maka hipotesis dalam penelitian ini yang dapat diajukan adalah:

$\mathrm{H}_{3}$ : Electronic word of mouth berpengaruh positif dan signifikan terhadap niat menggunakan kembali

\section{METODE PENELITIAN}

Untuk memahami pengaruh antara variabel yang mempengaruhi terhadap variabel yang dipengaruhi, maka metode asosiatiflah yang dipilih dan digunakan dalam penelitian ini. Wilayah Kota Denpasar yang dipilih sebagai lokasi penelitian, dengan obyek penelitiannya yaitu niat menggunakan kembali terhadap jasa Go-Food di Kota Denpasar yang dibentuk melalui variabel brand image, consumer satisfaction, serta electronic word of mouth. Adapun variabel independen atau bebas pada penelitian ini yaitu brand image $\left(\mathrm{X}_{1}\right)$, consumer 
satisfaction $\left(\mathrm{X}_{2}\right)$, serta e-WOM $\left(\mathrm{X}_{3}\right)$ sedangkan variabel dependennya yaitu niat menggunakan kembali (Y).

Tabel 2.

Rangkuman Instrumen Penelitian

\begin{tabular}{cll}
\hline Variabel & \multicolumn{1}{c}{ Indikator } & \multicolumn{1}{c}{ Sumber } \\
\hline Brand image & $\mathrm{X}_{1.1}$ Uniquenes & Shimp (2014: 40), \\
$\left(\mathrm{X}_{1)}\right.$ & $\mathrm{X}_{1.2}$ Favorable & Kotler dan \\
& $\mathrm{X}_{1.3}$ Dapat diandalkan & Amstrong (2012) \\
Consumer satisfaction & $\mathrm{X}_{2.1}$ Senang menggunakan produk & Prastiwi (2016), \\
$\left(\mathrm{X}_{2}\right)$ & $\mathrm{X}_{2.2}$ Dapat memuaskan kebutuhan & Herliza dan \\
& $\mathrm{X}_{2.3}$ Setia menggunakan produk & Saputri, (2016) \\
& $\mathrm{X}_{2.4}$ Tidak terlalu sensitif terhadap harga & \\
Electronic word of mouth & $\mathrm{X}_{3.1}$ Rekomendasi dari penggunam & \\
$\left(\mathrm{X}_{3}\right)$ & situs jejaring sosial. & Goyette et al \\
& $\mathrm{X}_{3.2}$ Komentar positif dari pengguna & (2010) \\
& jejaring sosial & \\
& $\mathrm{X}_{3.3}$ Informasi kualitas & \\
Niat menggunakan kembali & $\mathrm{Y}_{1.1}$ Minat transaksional & Soleha et al. \\
& $\mathrm{Y}_{2.2}$ Minat prefensial & (2017), (Chen \\
& $\mathrm{Y}_{2.3}$ Merekomendasikan & dan Hsieh, 2011) \\
\hline
\end{tabular}

Sumber: penelitian terdahulu, 2018

Masyarakat Kota Denpasar yang berusia 18 tahun, mengetahui jasa GoFood dan sebelumnya sudah pernah menggunakan jasa Go-Food yang jumlahnya tidak bisa dihitung secara pasti adalah populasi dari peneitian ini. Indikator yang dipergunakan pada penelitian ini berjumlah 13 indikator, adapun alasan ditentukannya indikator sebuah sampel tersebut berdasarkan Sugiyono (2018:165) yang menyatakan jumlah sampel yang dipergunakan dan ditentukan paling minimal 5-10 kali dari jumlah indikatornya untuk memperoleh data yang valid. Penelitian ini minimal membutuhkan sampel sebanyak 65 (13X5) dan maksimal 130 (13X10), penelitian ini mengambil 104 orang responden yang berarti sudah memenuhi kriteria. Purposive sampling dipergunakan dalam penelitian ini sebagai penentu sebuah sampel, data dalam penelitian ini bersifat kuantitatif dan kualitatif serta jenis data berlandaskan sumbernya yang dipakai untuk penelitian ini yaitu 
data primer dan skunder. Pengumpulan data dilaksanakan dengan mengedarkan kuisioner dan pengukuran atas jawaban responden menggunakan Skala Likert.

Analisis pada penelitian ini menggunakan analisis multiple linear regression yaitu guna menganalisis pengaruh antara variabel independen terhadap variabel dependen, serta penelitian ini memakai uji $\mathrm{F}$ dan uji t.

Adapun persamaan dari analisis multiple linear regression dapat dirumuskan sebagai berikut:

$\mathrm{Y}=\mathrm{b} 1 \mathrm{X} 1+\mathrm{b}_{2} \mathrm{X}_{2}+\mathrm{b}_{3} \mathrm{X}_{3}+\mathrm{e}$

Keterangan:

$\begin{array}{ll}\mathrm{Y} & =\text { niat menggunakan kembali } \\ \mathrm{b}_{1}, \mathrm{~b}_{2}, \mathrm{~b}_{3} & =\text { coefficient regresi } \\ \mathrm{X}_{1} & =\text { brand image } \\ \mathrm{X}_{2} & =\text { consumer satisfaction } \\ \mathrm{X}_{3} & =\text { electronic } \text { word of mouth } \\ \mathrm{e} & =\text { error distrurbance }\end{array}$

\section{HASIL DAN PEMBAHASAN}

Karakteristik responden ialah hasil keseluruhan data setelah dilakukannya pengumpulan guna mengetahui profil dari para responden penelitiannya. Adapun penelitian ini yang telah dilakukan terhadap konsumen Go-Food di Kota Denpasar, maka dapat dilihat karakter responden mencakupi empat aspek diantaranya ada usia, jenis kelamin, pendidikan serta pekerjaan. Pada Tabel 3 dibawah menunjukkan untuk karakteristik jenis kelamin didominasi oleh perempuan dengan persentase 53,8 persen. Karakteristik usia pada penelitian ini yang paling didominasi adalah pada usia 18-23 tahun dengan persentase sebesar 93,3 persen dan persentase paling rendah berada pada usia 24-29 tahun dengan 
persentase 6,7 persen. Karakteristik pendidikan pada penelitian ini kebanyakan dari kalangan SMA dengan persentase sebesar 73,1 persen dan persentase terendah sebesar 11,5 persen pada kalangan diploma. Karakteristik pekerjaan didominasi oleh kalangan mahasiswa dengan persentase sebesar 80,78 persen dan persentase terendah tertuju pada ibu rumah tangga sejumlah 0,96 persen.

Tabel 3.

Karakteristik Responden

\begin{tabular}{|c|c|c|c|c|}
\hline No. & Variabel & Klasifikasi & $\begin{array}{c}\text { Jumlah } \\
\text { Responden }\end{array}$ & $\begin{array}{c}\text { Persentase } \\
\text { (Persen) }\end{array}$ \\
\hline \multirow[t]{3}{*}{1.} & Jenis kelamin & Laki-laki & 48 & 46,2 \\
\hline & & Perempuan & 56 & 53,8 \\
\hline & & Jumlah & 104 & 100 \\
\hline \multirow[t]{3}{*}{2.} & Usia & 18-23 Tahun & 97 & 93,3 \\
\hline & & 24-29 Tahun & 7 & 6,7 \\
\hline & & Jumlah & 104 & 100 \\
\hline \multirow[t]{4}{*}{3.} & Pendidikan & SMA & 76 & 73,1 \\
\hline & & Diploma & 12 & 11,5 \\
\hline & & SI & 16 & 15,4 \\
\hline & & Jumlah & 104 & 100 \\
\hline \multirow[t]{5}{*}{4.} & Pekerjaan & Mahasiswa & 84 & 80,78 \\
\hline & & Wiraswasta & 17 & 16,34 \\
\hline & & PNS & 2 & 1,92 \\
\hline & & Ibu Rumah Tangga & 1 & 0,96 \\
\hline & & Jumlah & 104 & 100 \\
\hline
\end{tabular}

Menurut Sugiyono (2018:220) bahwa setiap instrumen dalam kuesioner dapat dinyatakan valid apabila koefisien korelasi $\geq 0,30$. Tabel 4 dibahwah menjelaskan bahwa masing-masing indikator variabel mempunyai nilai korelasi $\geq$ 0,30 maka hal tersebut dapat dinyatakan bahwa indikator dari pernyataan layak dipergunakan untuk menilai apa yang semestinya diukur serta dapat menyampaikan data dari variabel yang diteliti secara tepat serta dinyatakan valid sehingga instrumen penelitian pada penelitian ini layak untuk digunakan.

Uji reliabilitas juga telah dilaksanakan dalam penelitian ini, nilai suatu isntrumen dapat dinyatakan reliabel bila nilai dari Cronbach alpha $>0,6$. Hasil 
rekapitulasi pada Tabel 5. menjelaskan bahwa nilai Cronbach alpha masingmasing sudah memenuhi syarat, maka instrumen pada penelitian ini dapat dikatakan reliabel, serta apabila diterapkan kembali untuk mengukur obyek yang serupa alat ukurnya akan menghasilkan hasil yang konsisten.

Tabel 4.

Hasil Uji Validitas Instrumen

\begin{tabular}{lccc}
\hline \multicolumn{1}{c}{ Variabel } & Indikator & Korelasi & Keterangan \\
\hline Brand image & $\left(\mathrm{X}_{1.1}\right)$ & 0,946 & Valid \\
& $\left(\mathrm{X}_{1.2}\right)$ & 0,981 & Valid \\
Consumer satisfaction & $\left(\mathrm{X}_{1.3}\right)$ & 0,959 & Valid \\
& $\left(\mathrm{X}_{2.1}\right)$ & 0,927 & Valid \\
& $\left(\mathrm{X}_{2.2}\right)$ & 0,912 & Valid \\
& $\left(\mathrm{X}_{2.3}\right)$ & 0,889 & Valid \\
Electronic word of mouth & $\left(\mathrm{X}_{2.4}\right)$ & 0,665 & Valid \\
& $\left(\mathrm{X}_{3.1}\right)$ & 0,888 & Valid \\
& $\left(\mathrm{X}_{3.2}\right)$ & 0,853 & Valid \\
Niat menggunakan kembali & $\left(\mathrm{X}_{3.3}\right)$ & 0,922 & Valid \\
& $\left(\mathrm{Y}_{1.1}\right)$ & 0,915 & Valid \\
& $\left(\mathrm{Y}_{1.2}\right)$ & 0,929 & Valid \\
& $\left(\mathrm{Y}_{1.3}\right)$ & 0,921 & Valid
\end{tabular}

Sumber: data diolah, 2018

Tabel 5.

Rekapitulasi Hasil Uji Reliabilitas Instrumen

\begin{tabular}{lcc}
\hline \multicolumn{1}{c}{ Variabel } & Cronbach's Alpha & Keterangan \\
\hline Brand image $\left(\mathrm{X}_{1}\right)$ & 0,960 & Reliabel \\
Consumer satisfaction $\left(\mathrm{X}_{2}\right)$ & 0,862 & Reliabel \\
Electronic word of mouth $\left(\mathrm{X}_{3}\right)$ & 0,863 & Reliabel \\
Niat menggunakan kembali $(\mathrm{Y})$ & 0,910 & Reliabel \\
\hline Sumber: data diolah 2018
\end{tabular}

Sumber: data diolah, 2018

Tahap analisis regresi linear berganda Tabel 5. dibawah ini sudah dilakukan.

Untuk mengetahui pengaruh dari varaibel bebas atau independen (brand image $\mathrm{X}_{1}$, consumer satisfaction $\mathrm{X}_{2}$, serta e-WOM $\mathrm{X}_{3}$ ) terhadap varaibel terikat atau dependen (niat menggunakan kembali Y) maka dilakukanlah analisis regresi linear berganda.

Berdasarkan hasil rekapitulasi Tabel 6, maka diuraikan persamaan dari analisis regresi linear berganda sebagai berikut: 
$\mathrm{Y}=0,368\left(\mathrm{X}_{1}\right)+0,427\left(\mathrm{X}_{2}\right)+0,188\left(\mathrm{X}_{3}\right)$

Tabel 6.

Rekapitulasi Hasil Rangkuman Analisis Regresi

\begin{tabular}{lcc}
\hline Variabel & Standardized Coefficient & Sig. \\
\cline { 2 - 2 } & Beta & \\
\hline Brand image $\left(\mathrm{X}_{1}\right)$ & 0,368 & $.0,000$. \\
Consumer satisfaction $\left(\mathrm{X}_{2}\right)$ & 0,427 & $.0,000$. \\
Electronic word of mouth $\left(\mathrm{X}_{3}\right)$ & 0,188 & $.0,001$. \\
\hline Dependen variabel & $=$ Niat menggunakan kembali & \\
F Statistik & $=123,940$ & \\
Sig F & $=0,000$ & \\
$\mathrm{R}^{2}$ & $=0,778$ & \\
AdjustedR ${ }^{2}=0,782$ & & \\
\hline \multicolumn{2}{l}{ Sumber $:$ data diolah, 2018} &
\end{tabular}

Berdasarkan persamaan diatas maka pengaruh brand image, consumer satisfaction, electronic word of mouth terhadap niat menggunakan kembali dapat diartikan sebagai berikut:1) $\beta_{1}=0,368$; memiliki arti jika variabel brand image meningkat, maka akan mengakibatkan peningkatan terhadap niat menggunakan kembali, bersama anggapan variabel bebas lainnya dianggap konstan, 2) $\beta_{2}=$ 0,427 ; memiliki makna jika variabel consumer satisfaction meningkat, maka akan mengakibatkan peningkatan terhadap niat menggunakan kembali, bersama anggapan variabel bebas lainnya dianggap konstan, 3) $\beta_{3}=0,188$; memiliki arti jika variabel electronic word of mouth meningkat, maka akan mengakibatkan peningkatan terhadap niat menggunakan kembali, bersama anggapan variabel bebas lainnya dianggap konstan.

Penelitian ini juga sudah melakukan uji normalitas, dimana uji normalitas didapatkan dari Kolmogorov-smirnov dengan memperhatikan taraf signifikansinya lebih besar atau sama dengan 0,05. 
Tabel 7.

Rekapitulasi Hasil Uji Normalitas

\begin{tabular}{cc}
\hline & Unstandardized Residual \\
\hline $\mathrm{N}$ & 104 \\
Asymp. Sig (2-tailed) & 0,084 \\
\hline Sumber: data diolah, 2018
\end{tabular}

Berlandaskan uraian pada Tabel 7. dapat dilihat Asymp. Sig sebesar 0,084 > 0,05 maka dari itu dapat dinyatakan jika model regresinya pada penelitian ini terdistribusi secara normal.

Penelitian ini juga sudah melakukan uji multikolinearitas, dengan memperhatikan model regresi pada nilai VIFnya, nilai umum yang dipergunakan untuk memperlihatkan bahwa tidak terdapat multikolinearitas ialah nilai tolerancenya diatas 0,1 serta dengan nilai VIFnya dibawah 10.

Tabel 8.

Hasil Uji Multikolinearitas

\begin{tabular}{lcc}
\hline \multicolumn{1}{c}{ Variabel } & Tolerance & VIF \\
\hline Brand image $\left(\mathrm{X}_{1}\right)$ & 0,204 & 4,902 \\
Consumer satisfaction $\left(\mathrm{X}_{2}\right)$ & 0,202 & 4,940 \\
Electronic word of mouth $\left(\mathrm{X}_{3}\right)$ & 0,713 & 1,402 \\
\hline Sumber: data diolah, 2018 & &
\end{tabular}

Tabel 8. menjelaskan bahwa nilai VIFnya $<10$ serta memiliki angka tolerance $>$ dari 0,1 maka dapat dikatakan jika dalam penelitian ini model regresinya tidak terjadi multikolinearitas.

Penelitian ini juga melalui tahap uji heteroskedastisitas, uji Glejser adalah uji yang dipergunakan untuk mengukur adanya gejala heteroskedastisitas. Apabila penelitian ini tidak mengandung gejala heteroskedastisitas maka dapat dikatakan bahwa model regresinya baik dengan nilai signifikansinya $>0,05$. 
Tabel 9. Rekapitulasi Hasil Uji Heteroskedastisitas

\begin{tabular}{lc}
\hline \multicolumn{1}{c}{ Variabel } & Sig \\
\hline Brand image $\left(\mathrm{X}_{1}\right)$ & 0,593 \\
Consumer Satisfaction $\left(\mathrm{X}_{2}\right)$ & 0,219 \\
Electronic word of mouth $\left(\mathrm{X}_{3}\right)$ & 0,496 \\
\hline Sumber: data diolah, 2018 &
\end{tabular}

Pada Tabel 9 menjelaskan nilai signifikansi setiap variabel $>0,05$ maka hal tersebut menandakan bahwa tidak terjadinya gejala heteroskedastisitas pada model regresi ini.

Kemampuan suatu model dalam menjelaskan variasi variabel terikat merupakan tujuan dari koefisien regresi, model regresi dikatakan semakin baik apabila coefficient determinasinya semakin menuju angka 1.

Tabel 10.

Hasil Analisis Koefisien Determinasi

\begin{tabular}{cccc}
\hline $\mathrm{R}$ & $\mathrm{R}$ square & Adjusted R Square & $\begin{array}{c}\text { Std. Error of the } \\
\text { Estimate }\end{array}$ \\
\hline 0,888a & 0,788 & 0,782 & 0,964 \\
\hline Sumber: data diolah, 2018 & &
\end{tabular}

Pada Tabel 10. yang telah diuraikan, koefisien determinasi memiliki nilai sebesar 0,788 yang memiliki arti jika sebesar 78,8 persen variasi dari niat menggunakan kembali mampu dijelaskan oleh variabel brand image, consumer satisfaction, dan electronic word of mouth. Serta sisanya yang sebesar 21,2 persen dipengaruhi oleh faktor lainnya.

Uji $\mathrm{F}$ pada penelitian ini didasarkan atas hasil dari perhitungan analisis multiple linear regression yang telah dirangkup pada Tabel 6, diketahuinya $F_{\text {hitung }}$ sebesar 123,940 serta nilai signifikansinya sejumlah $0,000<0,05$ maka dapat dikatakan jika brand image $\left(\mathrm{X}_{1}\right)$, consumer satisfaction $\left(\mathrm{X}_{2}\right)$, e-WOM $\left(\mathrm{X}_{3}\right)$ secara 
bersamaan memiliki pengaruh yang signifikan terhadap niat menggunakan kembali(Y) jasa Go-Food di Kota Denpasar.

Uji t serta dilaksanakan pada penelitian ini yang dimaksudkan untuk menjelaskan dan mengetahui pengaruh variabel independen secara parsial terhadap variabel dependen. Apabila signifikansinya $\leq 0,05$ maka dapat dinyatakan bahwa variabel bebas mampu mempengaruhi variabel terikat secara parsial.

Tabel 11.

Rekapitulasi Hasil Analisis Uji t

\begin{tabular}{lccc}
\hline \multicolumn{1}{c}{ Variabel } & Thitung & Sig $\cdot$ & Hasil hipotesis \\
\hline Brand image $\left(\mathrm{X}_{1}\right)$ & 3,611 & 0,000 & $\mathrm{H}_{1}$ diterima \\
Consumer satisfaction $\left(\mathrm{X}_{2}\right)$ & 4,172 & 0,000 & $\mathrm{H}_{1}$ diterima \\
Electronic word of mouth $\left(\mathrm{X}_{3}\right)$ & 3,445 & 0,001 & $\mathrm{H}_{1}$ diterima \\
\hline
\end{tabular}

Sumber: data diolah, 2018

Adapun kriteria penilaiannya $\mathrm{H}_{0}$ diterima jika: tingkat signifikansi $>0,05$ (5 persen) serta $\mathrm{H}_{0}$ ditolak jika tingkat signifikansi $\leq 0,05$ (5 persen). Pada Tabel 11 menunjukkan bahwa; 1) nilai thitung pada brand image $\left(\mathrm{X}_{1}\right)$ sebesar 3,611 beserta nilai signifikansinya $0,000<$ dari 0,05 maka $\mathrm{H}_{1}$ diterima serta $\mathrm{H}_{0}$ ditolak, ini berarti bahwa brand image memiliki pengaruh yang positif serta signifikan terhadap niat menggunakan kembali jasa Go-Food di Kota Denpasar. 2) nilai thitung pada consumer satisfaction $\left(\mathrm{X}_{2}\right)$ sejumlah 4,172 beserta nilai signifikansinya $0,000<$ dari 0,05 maka $\mathrm{H}_{1}$ diterima serta $\mathrm{H}_{0}$ ditolak, ini berarti bahwa consumer satisfaction memiliki pengaruh yang positif serta signifikan terhadap niat menggunakan kembali jasa Go-Food di Kota Denpasar. 3) nilai thitung pada electronic word of mouth $\left(\mathrm{X}_{3}\right)$ sejumlah 3,445 dengan nilai signifikansi $0,001<$ 0,05 maka $\mathrm{H}_{1}$ dapat diterima dan $\mathrm{H}_{0}$ ditolak, ini berarti bahwa e-WOM 
mempunyai pengaruh yang positif serta signifikan terhadap niat menggunakan kembali jasa Go-Food di Kota Denpasar.

Berdasarkan tujuan penelitian, adapun tujuan pertama didalam penelitian ini yaitu untuk menjelaskan bagaimana pengaruh brand image terhadap niat menggunakan kembali pada jasa Go-Food di Kota Denpasar, berdasarkan hasil analisis koefisien brand image sebesar 0,368 serta tingkat signifikansinya sejumlah $0,000<0,05$ maka bisa dikatakan jika brand image memiliki pengaruh yang positif serta signifikan terhadap niat menggunakan kembali pada jasa GoFood di Kota Denpasar, ini berarti bahwa dibenak konsumen Go-Food memiliki brand image yang baik serta hal ini memperlihatkan jika semakin baik brand imagenya dari Go-Food maka akan semakin tinggi pula niat para costumer untuk mrnggunakan kembali jasa Go-Food di Kota Denpasar. Variabel brand image $\left(\mathrm{X}_{1}\right)$ yang diukur dengan mempergunakan tiga indikator yaitu, mengetahui keunggulan dari Go-Food $\left(\mathrm{X}_{1.1}\right)$, memiliki kemampuan merek yang tinggi sehingga mudah diingat oleh konsumen $\left(\mathrm{X}_{1.2}\right)$, dan pelayanan Go-Food dapat diandalkan $\left(\mathrm{X}_{1.3}\right)$. Hasil penelitian ini searah dengan penelitian yang telah diteliti oleh Aryadhe dan Rastini (2016) yang membuktikan jika brand image memiliki pengaruh yang signifikan terhadap niat menggunakan kembali, selain itu penelitian yang telah dilakukan oleh Shanyalak (2013) dan Apriyani (2013) yang membuktikan jika brand image mempunyai pengaruh yang signifikan terhadap niat menggunakan kembali dan membentuk sikap atau minat untuk menggunakan kembali pada konsumennya. 
Tujuan kedua dalam penelitian ini adalah untuk menerangkan pengaruh consumer satisfaction terhadap niat menggunakan kembali pada jasa Go-Food di Kota Denpasar. Berdasarkan hasil analisis yang telah diuraikan koefesien beta dari consumer satisfaction sebesar 0,427 serta nilai signifikansi sebesar 0,000 $<0,05$ maka dapat dinyatakan consumer satisfaction berpengaruh positif dan signifikan terhadap niat menggunakan kembali pada jasa Go-Food di Kota Denpasar, ini berarti bahwa konsumen merasakan kepuasan terhadap pelayanan jasa yang ditawarkan oleh Go-Food yang membuat konsumen ingin menggunakan kembali jasa Go-Food tersebut, disamping itu hasil dari penelitian ini membuktikan jika semakin tingginya tingkat consumer satisfaction maka akan semakin tinggi jua niat konsumen untuk menggunakan kembali jasa Go-Food di Kota Denpasar. Variabel consumer satisfaction $\left(\mathrm{X}_{2}\right)$ diukur dengan menggunakan empat indikator yaitu, senang menggunakan layanan jasa $\left(\mathrm{X}_{2.1}\right)$, dapat memuaskan kebutuhan $\left(\mathrm{X}_{2.2}\right)$, setia menggunakan jasa tersebut $\left(\mathrm{X}_{2.3}\right)$ dan tidak terlalu sensitf terhadap harga $\left(\mathrm{X}_{2.4}\right)$. Hasil penelitian ini searah dengan rumusan hipotesisnya yang menyatakan jika consumer satisfaction mempunyai pengaruh yang positif serta signifikan terhadap niat menggunakan kembali. Selain itu penelitian yang telah dilakukan oleh Fang et al. (2011), Huang et al. (2014), Kusuma dan Suryani (2017) yang membuktikan bahwa consumer satisfaction mempunyai pengaruh yang positif dan signifikan terhadap niat menggunakan kembali.

Tujuan yang ketiga dari penelitian ini ialah untuk menjelaskan pengaruh $e$ WOM terhadap minat menggunakan kembali jasa Go-Food di Kota Denpasar, dengan hasil analisis yang telah diuraikan sebelumnya adapun koefisien beta dari 
e-WOM sebesar 0,188 serta nilai signifikansi sebesar $0,001<0,05$ maka dapat dikatakan jika e-WOM mempunyai pengaruh yang positif dan signifikan kepada niat menggunakan kembali pada jasa Go-Food di Kota Denpasar, ini berarti bahwa konsumen merasa jika terdapat electronic word of mouth yang baik mampu meningkatkan niat konsumen untuk menggunakan kembali terhadap jasa Go-Food di Kota Denpasar, selain itu penelitian ini membuktikan jika semakin baiknya electronic word of mouth mengenai Go-Food maka semakin tinggi pula niat konsumen untuk menggunakan kembali jasa Go-Food di Kota Denpasar. Variabel electronic word of mouth $\left(\mathrm{X}_{3}\right)$ diukur dengan menggunakan tiga indikator yaitu, rekomendasi dari pengguna situs jejaring sosial $\left(\mathrm{X}_{3.1}\right)$, adanya komentar positive dari pengguna situs jejaring sosial $\left(\mathrm{X}_{3.2}\right)$, dan memiliki informasi kualitas $\left(\mathrm{X}_{3.3}\right)$. Hasil penelitian ini juga sejalan dengan rumusan hipotesis yang mengatakan jika electronic word of mouth mempunyai pengaruh positif serta signifikan terhadap niat menggunakan kembali pada jasa Go-Food di Kota Denpasar. Hasil dari penelitian ini juga searah dengan penelitian yang telah dilakukan oleh Liang et al. (2017), Matute et al. (2016), Arumsari dan Ariyanti (2017) juga sependapat dan membuktikan bahwa electronic word of mouth memiliki pengaruh yang positif serta signifikan terhadap niat menggunakan kembali.

\section{SIMPULAN DAN SARAN}

Mengenai hasil-hasil dari penelitian yang telah dijabarkan sebelumnya, maka simpulan yang didapat yaitu, brand image mempunyai pengaruh positif serta signifikan terhadap niat menggunakan kembali jasa Go-Food di Kota 
Denpasar. Berdasarkan uraian nilai beta dapat diketahui sebesar 0,368 serta tingkat signifikansinya $0,000<0,5$ maka hasil penelitian ini menyatakan jika semakin baiknya brand image dari Go-Food maka akan semakin tinggi jua niat konsumen untuk menggunakan kembali jasa Go-Food di Kota Denpasar. Selanjutnya ada variabel consumer satisfaction yang juga mempunyai pengaruh positif serta signifikan terhadap niat menggunakan kembali jasa Go-Food di Kota Denpasar. Perhitungan yang telah diuraikan sebelumnya dapat diketahui nilai beta sebesar 0,427 serta tingkat signifikansinya 0, 000 lebih kecil dari 0,05 maka hasil penelitian ini dapat dinyatakan dengan semakin tingginya consumer satisfaction (kepuasan konsumen) maka akan semakin tinggi pula niat konsumen untuk menggunakan kembali jasa Go-Food di Kota Denpasar. Selanjutnya dapat disimpulkan jika e-WOM mempunyai pengaruh yang positif serta signifikan terhadap niat menggunakan kembali jasa Go-Food di Kota Denpasar. Dengan hasil perhitungan yang telah dijabarkan jika nilai beta sebesar 0,188 dengan tingkat signifikansinya sebesar $0,001<0,05$ maka hasil dari penelitian ini dapat dinyatakan dengan semakin baiknya e-WOM mengenai Go-Food dijejaring sosial maka akan semakin tinggi jua niat konsumen untuk menggunakan kembali jasa Go-Food di Kota Denpasar.

Berdasarkan simpulan yang telah dijabarkan maka dapat diajukan beberapa saran, dimana PT. Aplikasi Karya Anak Bangsa yang menaungi Go-Food dapat melakukan berbagai inovasi-inovasi dengan cara memperbnyak driver, memperbaiki system order, serta memperbaiki system kerja driver agar sampai tepat dengan waktunya dalam membawakan orderan kepada konsumen, dengan 
memperbaiki hal tersebut konsumen akan merasa bahwa pelayanan jasa Go-Food lebih dapat diandalkan serta hal tersebut dapat menimbulkan kepuasan konsumen yang akan meningkatkan niat menggunakan kembali jasa Go-Food. PT Aplikasi Karya Anak Bangsa yang menaungi Go-Food dapat memberikan gambaran kualitas pelayanan dari Go-Food secara spesifik baik itu melalui website, maupun sosial media lainnya dan dapat dibuat dengan semenarik mungkin agar konsumen lebih tertarik untuk mencari atau membentuk e-WOM positif di jejaring sosial.

PT Aplikasi Karya Anak Bangsa yang menaungi Go-Food perlu lebih menonjolkan brand image, serta membangun e-WOM yang psoitif di jejaring sosial dan memberikan perhatian kepada kepuasan konsumennya (consumer satisfaction) sehingga nantinya dapat berimplikasi terhadap niat menggunakan kembali jasa Go-Food dan tidak menutup kemungkinan konsumen yang sudah pernah menggunakan jasa Go-Food akan merekomendasikan atau membawa calon pelanggan baru dalam jumlah yang lebih banyak untuk menggunakan GoFood dan menjadikannya sebagai pilihan utama konsumen. Hal tersebut akan memberikan keuntungkan yang berlipat untuk perusahaan dan dapat memperkokoh brand yang kuat didalam benak konsumen.

Untuk peneliti berikutnya diharapkan bisa memakai variabel berbeda atau menambahkan variabel lainnya misalnya seperti kualitas jasa, pengalaman konsumen, kepercayaan konsumen dan masih banyak lagi. Penelitian kedepannya juga diharapkan dapat memperluas ruang lingkup penelitian dan melakukan penelitian secara periodic (time series) agar memperoleh hasil penelitian yang riil dan aktual. 


\section{REFERENSI}

Apriyani, Y. (2013). Pengaruh Brand Image , Harga dan Kualitas Pelayanan Terhadap Keputusan Pembelian Ulang Pizza Hut di Kota Padang. Manajemen, 2(1), 1-10.

Arumsari, R., \& Ariyanti, M. (2017). The Effect of Electronic Word of Mouth , Brand Image, Customer Trust and Customer Satisfaction Towards Repurchase Intention at PT . GO-JEK Indonesia. International Journal of Science and Research (IJSR), 1(7), 1732-1737. https://doi.org/10.21275/ART20175247

Aryadhe, P., \& Rastini, N. M. (2016). Kualitas Pelayanan, Kualitas Produk dan Citra Merek terhadap Niat Beli Ulang di PT AgungToyota Denpasar. EJurnal Manajemen Unud, 5(9), 5695-5721.

Badan Pusat Statistik Provinsi Bali. 2018. Penduduk Provinsi Bali Menurut Kabupaten/Kota, Jenis Kelamin, dan Status Migrasi Seumur Hidup Hasil Sensus Penduduk 2010. https://bali.bps.go.id/ statistictabel/2018/02/15/37/ penduduk-provinsi-bali-menurut-kabupaten-kota-jenis-kelamin-dan-statusmigrasi-seumur-hidup-hasil-sensus-penduduk-2010.html, diakses pada bulan Mei 2018.

Chen, H.-S., \& Hsieh, T. (2011). A Study of Antecedents of Customer Repurchase Behaviors in Chain Store Supermarkets. Journal of International Management Studies, 6(3), 1-11.

Eriza, Z. N. (2017). Peran Mediasi Citra Merek dan Persepsi Risiko Pada Hubungan Antara Electronic Word Of Mouth ( e-WOM ) dan Minat Beli ( Studi Pada Konsumen Komsutif E-Commerce di Solo Raya). Komuniti, 9(1), $14-24$.

Fang, Y. H., Chiu, C. M., \& Wang, E. T. G. (2011). Understanding customers' satisfaction and repurchase intentions: An integration of IS success model, trust, and justice. Internet Research, 21(4), 479-503. https://doi.org/10.1108/10662241111158335

Fauziah, A. (2017). Kajian Psikolinguistik Pada Proporsi Citra Merek. Jurnal Penelitian Ilmu Ekonomi WIGA, 7(2), 132-142.

GOFOOD: Aplikasi Pesan Antar Makanan Online 24 Jam. 2017. https://www.gofood.co.id/, diakses pada bulan Mei 2018.

Goyette, I., Ricard, L., Bergeron, J., \& Marticotte, F. (2010). e-WOM Scale: Word-of-Mouth Measurement Scale for e-Services Context. Canadian Journal of Administrative Science, 27(1), 5-23. 
https://doi.org/10.1002/cjas.129

Herliza, R., \& Saputri, M. E. (2016). Pengaruh Brand Image terhadap Kepuasan Pelanggan Studi Pada ZARA di Mall PVJ Bandung. E-Proceeding of Management, 3(2), 1949-1955.

Huang, C., Yen, S., Liu, C., \& Chang, T. (2014). The Relationship Among Brand Equity, Customer Satisfaction, and Brand Resonance To Repurchase Intention of Cultural and Creative Industries in Taiwan. The International Journal of Organization Innovation, 6(3), 106-121. https://doi.org/10.1109/ASPDAC.2007.357995

Humaira, A., \& Wibowo, L. A. (2016). Analisis Faktor Elektronik Word of Mouth (EWOM) Dalam Mempengaruhi Keputusan Pembelian Berkunjung Wisatawan. Tourism and Hospitality Essentials (THE) Journal, 6(2), 10491060 .

Jhon C. Mowen, Michael Minor. 2010. Perilaku Konsumen. Jakarta : Erlangga.

Keluhan dan Saran untuk Go-Jek. https://keluhan-gojek.ojekgratis.com, diakses pada bulan Mei 2018.

Kim, H. D., \& Lough, N. (2007). An Investigation into Relationships among Constructs of Service Quality, Customer Satisfaction, and Repurchase Intention in Korean Private Golf Courses. The ICHPER SD Journal of Research, 1(2), 14-22.

Kusuma, P. D., \& Suryani, A. (2017). Peran Customer Satisfaction Memediasi Pengaruh Marketing Mix terhadap Repurchase Intention. E-Jurnal Manajemen Unud, 6(3), 1398-1424.

Liang, L. J., Choi, H. C., \& Joppe, M. (2017). Understanding Repurchase Intention of Airbnb Consumers: Perceived Authenticity, Electronic Word-ofMouth, and Price Sensitivity. Journal of Travel and Tourism Marketing, 35(1), 73-89. https://doi.org/10.1080/10548408.2016.1224750

Matute, J., Polo-Redono, Y., \& Utrillas, A. (2016). The influence of EWOM characteristics on online repurchase intention Mediating roles of trust and perceived usefulness. International Journal Logistics Management, 40(7), 1090-1110. https://doi.org/10.1108/09574090910954864

Nurhayati, \& Murti, W. W. (2012). Analisis Faktor-Faktor yang Mempengaruhi Minat Beli Ulang Masyarakat Terhadap Produk handphone. Jurnal Bisnis Dan Manajemen, 8(2), 1693 - 3435. 
Parastanti, G. P., Kumadji, S., \& Hidayat, K. (2014). Pengaruh Prior Online Purchase Experience terhadap Trust dan Online Repurchase Intention (Survey pada Pelanggan ZALORA Indonesia Melalui Website www.zalora.co.id). Jurnal Administrasi Bisnis (JAB), 16(1), 1-7. Retrieved fromhttp://download.portalgaruda.org/article.php?article $=265107 \& \mathrm{val}=6468$ \&title=PENGARUH PRIOR ONLINE PURCHASE EXPERIENCE TERHADAP TRUST DAN ONLINE REPURCHASE INTENTION (Survey pada Pelanggan ZALORA Indonesia Melalui Website www.zalora.co.id).

Prastiwi, S. K. (2016). Menguji Faktor-Faktor Yang Berpengaruh Terhadap Repurchase Intention Pada Produk Mie Instan Indomie Di Yogyakarta. Jurnal EKA CIDA Vol., 1(1), 96-109.

Putra, A. B., Lapian, J., \& Lumanauw, B. (2014). Bauran Pemasaran Pengaruhnya terhadap Minat Membeli Kembali Voucher Isi Ulang Telkomsel. Jurnal EMBA, 2(3), 428-437. https://doi.org/10.5604/01.3001.0009.7374

Raharjo, C. A., \& Amboningtyas, D. (2017). The Effect of Service Quality, Price and Brand Image on Consumer Loyalty with Customer Satisfaction as Moderating on The Point "Barokah" Sikopek. Journal of Management, 3(3), $1-6$.

Sari, N. K. L., \& Santika, I. W. (2013). Pengaruh Brand Image, Brand Association, dan Brand Awarness terhadap Repurchase Intention Produk Smartphone Merek Asus. E-Jurnal Manajemen Unud, 29(3), 190-195. https://doi.org/10.1089/vim.2017.0075

Sembiring Inka Janita, S., \& Kusumawati, A. (2014). Kepuasan Pelanggan dalam Membentuk Loyalitas Pelanggan ( Studi pada Pelanggan McDonald 's MT . Haryono Malang ). Jurnal Administrasi Bisnis (JAB), 15(1), 1-10.

Shahrinaz, I., Kusuma, J., Yacob, Y., Rahman, D. H. A. A., \& Mahdi, A. F. (2016). Relationship and Impact of e-WOM and Brand Image Towards Purchase Intention of Smartphone? Journal of Scientific Research and Development, 3(5), 117-124.

Shanyalak Sangkatat Na Ayutthaya. (2013). Impact of Perceived Service on Brand Image and Repurchase Intentions of Thai Passengers Towards Low Cost Carriers. Au Journal of Management, 11(2), 46-56.

Soleha, I., Arifin, R., \& S, A. R. (2017). Pengaruh Citra Merek dan Persepsi label Halal terhadap Minat Pembelian Ulang Produk Kosmetik Zoya Malang. Jurnal Riset Manajemen, 6(2), 166-176. https://doi.org/10.1123/ijsb.8.1.1 
Sotiriadis, M. D., \& van Zyl, C. (2013). Electronic Word-of-Mouth and Online Reviews in Tourism Services: The Use of Twitter by Tourists. Electronic Commerce Research, 13(1), 103-124. https://doi.org/10.1007/s10660-0139108-1

Srivastava, K., \& Sharma, N. K. (2013). Service Quality, Corporate Brand Image, and Switching Behavior: The Mediating Role of Customer Satisfaction and Repurchase Intention. Services Marketing Quarterly, 34(4), 274-291. https://doi.org/10.1080/15332969.2013.827020

Sugiyono. 2018. Metodelogi Penelitian Manajemen. Bandung: Alfabeta

Torlak, O., Ozkara, B. Y., Tiltay, M. A., Cengiz, H., \& Dulger, M. F. (2014). The Effect of Electronic Word of Mouth on Brand Image and Purchase Intention: An Application Concerning Cell Phone Brands for Youth Consumers in Turkey. Marketing Intelligence \& Planning, 30(4), 460-476. https://doi.org/10.1108/02634501211231946

Top Brand Award. 2016. Top Brand Fase 2. https://www.topbrandaward.com/top-brand-survey/survey-result/top_brand_index_2016_fase_2, diakses pada bulan Mei 2018.

2017. Top Brand Fase 2. https://www.topbrand-award.com/topbrand-survey/survey-result/top brand index 2017 fase 22, diakses pada bulan Mei 2018.

Umamy, C., Kumadji, S., \& Yulianto, E. (2016). Pengaruh Electronic Word of Mouth Teradap Brand Image serta Dampaknya pada Minat Beli ( Survei pada Mahasiswa Universitas Brawijaya Malang Angkatan 2015 / 2016 Pengguna Smartphone ). Jurnal Administrasi Bisnis, 33(1), 114-119.

Vigripat, T., \& Chan, P. (2007). An Empirical Investigation of the Relationship Between Service Quality, Brand Image, Trust, Customer Satisfaction, Repurchase Intention and Recommendation to Others. International DSI / Asia and Pacific DSI. https://doi.org/10.1007/s11571-009-9078-0 